Tropical Journal of Pharmaceutical Research December 2020; 19 (12): 2565-2570

ISSN: $1596-5996$ (print); 1596-9827 (electronic)

(C) Pharmacotherapy Group, Faculty of Pharmacy, University of Benin, Benin City, 300001 Nigeria.

Original Research Article

http://dx.doi.org/10.4314/tjpr.v19i12.12

\title{
Bacoside-A exerts protective effect against Parkinson's disease-induced functional damage in mice via inhibition of apoptosis and oxidative response
}

\author{
Binbin Zhang ${ }^{1,2}$, Jiankuan $\mathrm{Shi}^{3}$, Lei Chang ${ }^{4}$, Hong Wang ${ }^{5}$, Yaping Wang ${ }^{6}$, Minxia \\ $\mathrm{Li}^{3}$, Yuying $\mathrm{Li}^{1}$, Yijun Song ${ }^{1 *}$ \\ ${ }^{1}$ Department of Neurology, Tianjin Medical University General Hospital, Tianjin 300052, '2Department of Neurology, Dongli \\ Hospital, Dongli District, Tianjin 300300, ${ }^{3}$ Department of Neurology, Xi'an International Medical Center Hospital, Xi'an, Shaanxi \\ 710100, ${ }^{4}$ Department of Neurology, The Third Hospital of Weinan City, Weinan, Shaanxi 714100, ${ }^{5}$ Department of Neurology, \\ Tianjin Academy of Traditional Chinese Medicine Affiliated Hospital, Tianjin 300120, ${ }^{6}$ Department of No.3 Cardiology, Shanxi \\ Provincial People's Hospital, Xi'an, Shaanxi 710068, China
}

*For correspondence: Email: songyijun2000@126.com

\begin{abstract}
Purpose: To determine the effect of bacoside-A on Parkinson's disease (PD) in a rat model, and elucidate its mechanism of action.

Methods: A rat model of PD was established by administration of $5 \mu \mathrm{L}$ of 6 -hydroxydopamine in ascorbic acid (0.1\%). Measurement of serum levels of inflammatory factors was carried out using enzyme-linked immunosorbent assay (ELISA) kits. Western blotting was used to assay Bax, cytochrome $\mathrm{c}$ and $\mathrm{Bcl}-2$ in rat hippocampus.

Results: Bacoside-A treatment significantly reduced $P D$-induced high turning values in rats $(p<0.05)$. Treatment with bacoside-A reversed PD-mediated suppression of serum activities of CAT and glutathione peroxidase (GPX). In bacoside-A-treated $P D$ rats, dose-dependent suppression of acetylcholinesterase (AChE) and inducible nitric oxide synthase (iNOS) activities were observed ( $p<$ $0.05)$. Bacoside-A-treated $P D$ rats significantly $(p<0.018)$ reduced interleukin (IL)-1 $\beta$ and IL-6 levels. Treatment of $P D$ rats with bacoside- $A$ effectively reduced levels of tumor necrosis factor (TNF)- $\alpha, N F-\kappa B$ p65, (COX)-2 and 053 protein, and also reversed up-regulations of Bax, cytochrome $C$, caspase-3 and caspase-9.

Conclusion: Bacoside-A exhibits a protective effect against Parkinson disease-induced oxidative damage and neuronal degeneration in rats through downregulation of iNOS, AChE, inflammatory cytokines and pro-apoptotic proteins. Therefore, bacoside-A has potentials for use in the management of Parkinson disease.
\end{abstract}

Keywords: Parkinson disease, Neuroprotective, Pro-apoptotic, Cytokines, Neurotoxicity

This is an Open Access article that uses a funding model which does not charge readers or their institutions for access and distributed under the terms of the Creative Commons Attribution License (http://creativecommons.org/licenses/by/4.0) and the Budapest Open Access Initiative (http://www.budapestopenaccessinitiative.org/read), which permit unrestricted use, distribution, and reproduction in any medium, provided the original work is properly credited.

Tropical Journal of Pharmaceutical Research is indexed by Science Citation Index (SciSearch), Scopus, International Pharmaceutical Abstract, Chemical Abstracts, Embase, Index Copernicus, EBSCO, African Index Medicus, JournalSeek, Journal Citation Reports/Science Edition, Directory of Open Access Journals (DOAJ), African Journal Online, Bioline International, Open-J-Gate and Pharmacy Abstracts

\section{INTRODUCTION}

Parkinson's disease (PD) is the second most frequently diagnosed neurodegenerative disorder after Alzheimer's disease [1, 2]. The pathogenesis of PD starts with degeneration of dopamine neurons present in the substantia nigra pars compacta, followed by aggregation of 
ubiquitinated a-synuclein in the other neurons [1]. Attempts are being made to identify effective and therapeutic agents, and molecular targets for use in the development of treatment strategies for neurodegenerative disorders [3]. Unfortunately, no effective therapeutic agents are available for the treatment of neurodegenerative disorders till date. Thus, there is need for development of novel therapeutic strategies for these disorders.

Parkinson's disease (PD) ultimately leads to oxidative stress-mediated cell injury which severely affects the lives of patients [4]. It is believed that inhibition of free radical production is of great importance for prevention of neurodegenerative disorders [5]. The hydrolysis of acetylcholine by acetylcholinesterase (AChE) leads to the termination of nerve impulses [6]. Studies have shown that AChE enhances apoptosis of cells, and its inhibition plays therapeutic role in PD by preventing dopaminergic neuronal death [6]. Thus, the inhibition of AChE activity prevents dopaminergic neurotoxicity in vitro and in vivo [6].

Bacopa monniera has a history of use in traditional medicine for enhancing memory and preventing epileptic disorders [7]. Phytochemical investigation of Bacopa monniera revealed the presence of many potent secondary metabolites such as betulinic acid, stigmasterol and bacosides, and subsequent studies revealed that its cognitive improvement property was associated with bacosides $A$ and $B$ [8]. The present study determined the neuroprotective effect of bacoside-A in a rat model of Parkinson's disease induced by 6hydroxydopamine, and investigated its mechanism of action.

\section{EXPERIMENTAL}

\section{Animals and experimental design}

A total 50 male Wistar rats weighing 295 - $340 \mathrm{~g}$ (8 - 10 weeks of age) were supplied by Vital River Laboratories, Beijing China. The rats were housed in an animal center under controlled temperature of $23-24{ }^{\circ} \mathrm{C}$ and $65 \%$ humidity. All rats were exposed to 12-h light/12-h dark cycles and given ad libitum access to feed and water. The rats were assigned randomly to five groups namely: sham group, model group, and three bacoside-A treatment groups i.e. 5, 10 and 20 $\mathrm{mg} / \mathrm{kg}$. The treatment groups were given bacoside-A intraperitoneally at doses of 5, 10 and $20 \mathrm{mg} / \mathrm{kg} 24$ hours prior to PD induction. Rats in sham and model groups received equivalent volumes of normal saline at the same time, in place of drug. The experimental procedures on rats were carried out in accordance with the guidelines of the National Institute of Health, China [6]. The study received approval from the Ethics Committee for Animal Care and Welfare, Tianjin Medical University General Hospital, Tianjin, China (approval no. SU/17/007).

\section{Establishment of PD rat model}

The rats were anesthetized with pentobarbital sodium at a dose of $30 \mathrm{mg} / \mathrm{kg}$ intraperitoneally. A hole was carefully drilled in the cranial cavity of each rat, and a needle was inserted in right side of the substantia nigra pars compacta. Then, $5 \mu \mathrm{L}$ of 6 -hydroxydopamine in $0.1 \%$ ascorbic acid ( $2 \mu \mathrm{g} / \mu \mathrm{L})$ was administered to the rats, except those in sham group.

\section{Rotational behavior test}

Rotational testing of the rats was performed over a duration of 30 min 14 days after surgery. The rotational test and measurement of lesion volumes were performed to determine the severity of behavioral disorder. In this test, the rats were rotated through $360^{\circ}$ to the ipsilateral and contralateral sides.

\section{Measurement of oxidative stress}

Blood samples of the rats were taken on day 31 of treatment and centrifuged at $4^{\circ} \mathrm{C}$ for $15 \mathrm{~min}$ at $5,000 \times \mathrm{g}$ to obtain sera. Microplate readers (LLC, Sunnyvale, CA, USA) were used for measurement of absorbance of the serum samples at $455 \mathrm{~nm}$. Assays of serum CAT, GSH-Px, TNF- $\alpha$, IL- $1 \beta, \quad$ IL- 6 and NF-kB p65 were carried out using assay kits from Nanjing Jiancheng Bioengineering Institute (Nanjing, China) according to manufacturer's instructions.

\section{Determination of activities of iNOS and AChE}

The rats were sacrificed on day 31 of treatment following administration of chloral hydrate at a dose of $350 \mathrm{mg} / \mathrm{kg}$ through the intraperitoneal route. The rat brains were excised carefully to isolate the hippocampal tissues for determination of activities of iNOS and AChE. The hippocampal tissues were rinsed in PBS and homogenized with ice-cold RIPA buffer (Beyotime Institute of Biotechnology, Nanjing, China) containing protease inhibitors. The homogenates were subjected to centrifugation for $20 \mathrm{~min}$ at $1200 \mathrm{~g}$, and the protein contents of the supernatants were measured with bicinchoninic acid assay kit. The activities of 
iNOS and AChE in supernatants were assayed with ELISA kits (Nanjing Jiancheng Bioengineering Institute) as per the supplier's protocols. Absorbance was read at $465 \mathrm{~nm}$ in a microplate reader (Molecular Devices LLC).

\section{Western blotting}

Portions of hippocampal tissues were homogenized with ice-cold RIPA buffer in combination with protease inhibitor mixture. The homogenates were subjected to centrifugation for $20 \mathrm{~min}$ at $1200 \mathrm{~g}$, and the protein contents of the supernatants were measured with bicinchoninic acid assay kit. Then, $30-\mu \mathrm{g}$ protein samples were resolved on SDS-polyacrylamide gel $(10-12 \%)$ and subsequently transferred to PVD membranes. Incubation was performed overnight at $4^{\circ} \mathrm{C}$ with primary antibodies against Bax (1:500 dilution), cytochrome c (1:500 dilution) and $\beta$-actin (1:4,000 dilution), all from Santa Cruz Biotechnology, Inc. (Dallas, TX, USA).

After washing with TBS- Tween-20, the membranes were incubated with Ig-conjugated secondary antibody (1:5,000 dilution) at room temperature for $1 \mathrm{~h}$. Chemiluminescence detection kit was used for visualization of the immunoreactive bands, while ImageJ software v3.0 was employed for quantification.

\section{Statistical analysis}

The data are presented as mean \pm standard deviation of three measurements, and statistical analysis was carried out using SPSS 20.0 (IBM Corp., Armonk, NY, USA). Differences were determined statistically using one-way analysis of variance, followed by Tukey's post hoc test. Differences were considered statistically significant at $p<0.05$.

\section{RESULTS}

\section{Bacoside-A improved PD-induced rotational behavioral changes}

In PD rats, the turning value increased significantly $(p<0.049)$ compared to the sham group (Figure 1). Bacoside-A treatment significantly $(p<0.049)$ decreased the PDinduced higher turning values in rats in a dosebased manner. The PD-induced higher turning values were significantly suppressed by bacoside-A treatment at doses of 5 and 10 $\mathrm{mg} / \mathrm{kg}$. However, at 20 a dose of $\mathrm{mg} / \mathrm{kg}$, bacoside-A completely eliminated the PDinduced increase in turning values in the rat model.

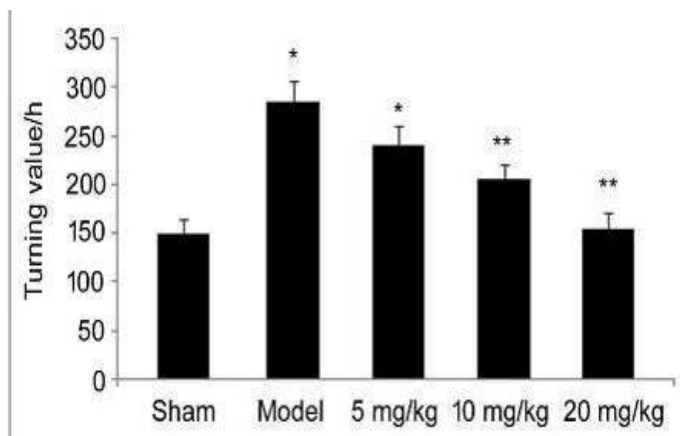

Figure 1: Effect of bacoside-A on rotational behavior of PD rats. The PD-induced changes in rotational behavior were determined in rats treated with bacoside at doses of 5,10 and $20 \mathrm{mg} / \mathrm{kg}$. ${ }^{*} P<0.05$; ${ }^{* *} p<0.02$, vs. model group

\section{Bacoside-A elevated CAT and GSH-PX activities in PD rats}

The activity of CAT in PD rats was suppressed significantly $(p<0.049)$, when compared to that in the sham control group (Figure 2 A). In addition, GPx level was reduced significantly ( $p$ $<0.049$ ) in PD rats relative to sham group (Figure 2 B). However, bacoside-A mitigated PD-mediated suppression of CAT as well as GPx levels in a dose-dependent manner. In rats treated with $20 \mathrm{mg} / \mathrm{kg}$ bacoside-A, the PDmediated suppressions of CAT and GPx activities were effectively reversed.

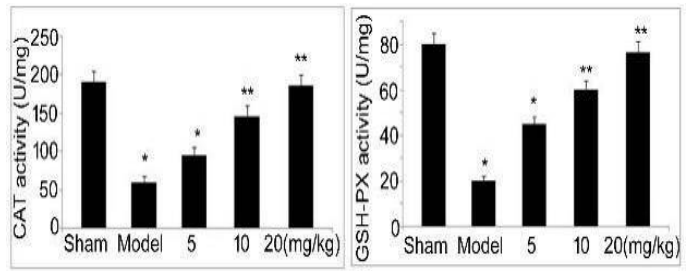

Figure 2: Effect of bacoside-A on levels of CAT and GPX in PD rats. Serum of PD rats treated with bacoside-A at doses of 5,10 and $20 \mathrm{mg} / \mathrm{kg}$ was assayed for CAT (A) and GPx (B) activities. ${ }^{*} P<$ $0.049 ;{ }^{* *} p<0.018$, vs. model group

\section{Bacoside-A inhibited activities of AChE and iNOS in PD rats}

The activities of AChE and iNOS in PD rats were markedly increased $(p<0.049)$, relative to those in sham group (Figure 3 ). In PD rats, bacoside-A suppressed the activities of AChE and iNOS dose-dependently. Bacoside-A treatment at a dose of $20 \mathrm{mg} / \mathrm{kg}$ suppressed AChE and iNOS activities in PD rats to levels close to those of the sham group. 


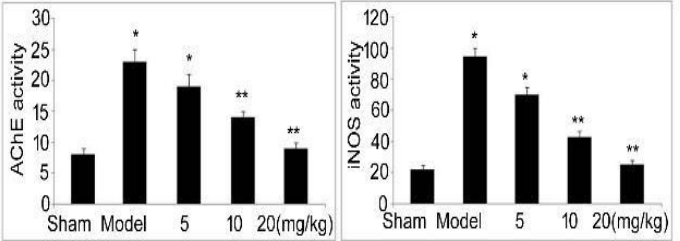

Figure 3: Effect of bacoside-A on AChE and iNOS activities in PD rats. Hippocampal tissues of PD rats treated with bacoside-A at doses of 5,10 and 20 $\mathrm{mg} / \mathrm{kg}$ were assayed for ACheE (A) and iNOS (B) levels. ${ }^{\star} P<0.049 ;{ }^{* *} p<0.018$, vs. model group

\section{Bacoside-A suppressed inflammation in PD rats}

In PD rat model, marked elevations were observed in the levels of IL-1 $\beta$ and IL-6, relative to the sham group (Figure 4). However, bacoside-A significantly and dose-dependently decreased the levels of IL-1 $\beta$ and IL-6 $(p<$ 0.018 ). The PD-mediated elevations in IL-1 $\beta$ and IL-6 were effectively reversed by bacoside- $A$ at a dose of $20 \mathrm{mg} / \mathrm{kg}$. Moreover, TNF- $\alpha$ and NF-KB p65 levels were significantly increased in PD rats, relative to the sham group $(p<0.049)$. However, treatment of PD rats with bacoside-A caused reductions in TNF- $\alpha$ and NF-KB p65 levels in a dose-based manner.

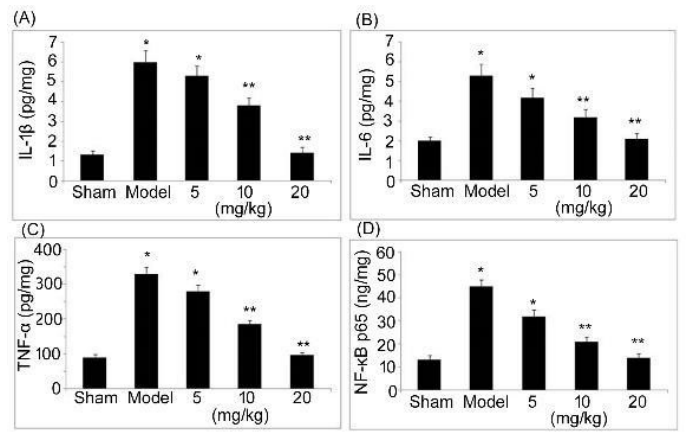

Figure 4: Effect of bacoside-A on levels of inflammatory markers. Serum of PD rats treated with bacoside- $A$ at doses of 5,10 and $20 \mathrm{mg} / \mathrm{kg}$ was assayed for (A) IL-1 $\beta$, (B) IL-6, (C) TNF- $\alpha$ and (D) NFkB p65. ${ }^{*} P<0.049 ;{ }^{* *} p<0.018$, vs. model group

\section{Bacoside-A inhibited COX-2 and p53 protein levels in PD rats}

The protein levels of COX-2 and p53 were increased markedly in PD rats, relative to the sham group (Figure 5). However, significant reductions in COX-2 and p53 protein levels in PD rats were observed on treatment with bacoside-A. The COX-2 and p53 protein levels in $20 \mathrm{mg} / \mathrm{kg}$ bacoside-A-treated PD rats were comparable to those in the sham group.

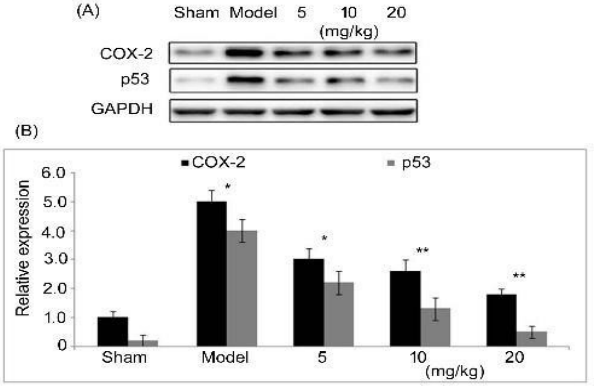

Figure 5: Effect of bacoside-A on protein levels of COX-2 and p53 in PD rats. (A) COX-2 and p53 protein levels in $\mathrm{PD}$ rats treated with bacoside-A at doses of 5,10 and $20 \mathrm{mg} / \mathrm{kg}$. (B) Quantified data on protein expressions of COX-2 and p53. GAPDH was used as internal control. ${ }^{*} P<0.049$; ${ }^{* *} p<0.018$, vs. model group

\section{Bacoside-A suppressed Bax, caspase- 3 and -9 activity in $P D$ rats}

In PD rats, there were marked increases in the expressions of Bax, caspase- 3 and caspase-9, relative to the sham group (Figure 6). However, treatment of PD rats with bacoside-A mitigated the up-regulation of Bax, caspase 3 and caspase- 9 in a dose-dependent manner. The suppressions were significant in PD rats treated with bacoside doses of 5 and $10 \mathrm{mg} / \mathrm{kg}$, relative to untreated group.

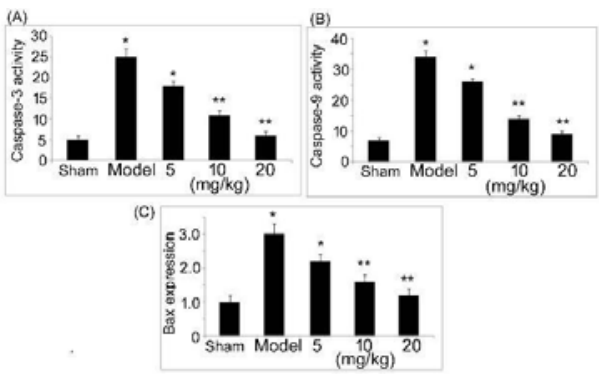

Figure 6: Effect of bacoside-A on the expression levels of Bax, caspase-3 and caspase-9. Protein expression levels of Bax, caspase- 3 and caspase- 9 in PD rats treated with bacoside at doses of 5,10 and $20 \mathrm{mg} / \mathrm{kg}$ were assayed using western blotting, with GAPDH as internal control. ${ }^{*} P<0.049 ;{ }^{* *} p<0.018$, vs. model group

\section{Bacoside-A inhibited cytochrome C in PD rats}

Cytochrome c activation was elevated markedly in PD rat model, relative to that in the sham group (Figure 7). Bacoside-A treatment significantly reversed PD-induced elevation of cytochrome $c$ activation in the PD rats. In PD rats treated with bacoside at a dose of $20 \mathrm{mg} / \mathrm{kg}$, the activation of cytochrome $c$ was suppressed to a value close to that of the sham group.

Trop J Pharm Res, December 2020; 19(12): 2568 


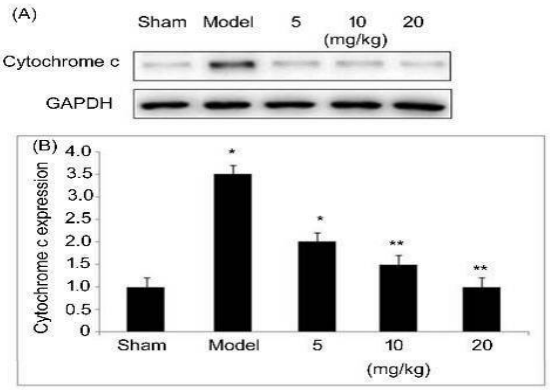

Figure 7: Effect of bacoside-A on cytochrome c activation in PD rats. (A) Cytochrome c protein levels in PD rats treated with bacoside at doses of 5,10 and $20 \mathrm{mg} / \mathrm{kg}$, as assayed using western blotting. (B) Data on quantified protein expressions. GAPDH was used as internal control. ${ }^{\star} P<0.049 ;{ }^{* *} p<0.018$, vs. model group

\section{DISCUSSION}

Parkinson's disease, also called paralysis agitans, globally affects $10 \%$ of people aged $>65$-years $[9,10]$. It is a chronic and progressive disorder of the nervous system arising from functional defects in the extrapyramidal system $[9,10]$. Oxidative response associated with the depletion of antioxidants and over-production of oxidative radicals causes severe damage to cells [11]. It has been found that neurons present in the substantia nigra pars compacta are highly susceptible to oxidative stressinduced cellular damage [4]. In the present study, the turning value of the PD rat model was significantly higher than that of rats in the sham group. however, the turning value was decreased effectively and dose-dependently by bacoside-A. Moreover, the PD rats had suppressed serum levels of CAT and GPx, relative to the vehicle-treated group. These findings reveal that bacoside-A decreased turning value in $P D$ rats through enhancement of the anti-oxidant enzymes CAT and GPx. It has been revealed that AChE contributes significantly to apoptosis [12]. Thus, downregulation of $A C h E$ is vital in neuroprotective therapies through anti-apoptotic mechanism [13]. Imbalance between dopamine and acetylcholine is associated with the pathogenesis of PD [13]. In mice models, the anti-inflammatory properties of therapeutic agents have been linked to inhibition of AChE [14]. Inflammation and disruption of the blood brain barrier enhance the interaction between the CNS and peripheral immune system, resulting in increased accumulation of leukocytes in brain parenchyma [15].

Accumulation of peripheral immune cells in the CNS leads to neuronal degeneration through paracrine and endocrine pathways [16]. In the present study, PD rats had enhanced AChE activity in hippocampal tissues. However, bacoside-A treatment exerted suppressive effect on AChE activities in the hippocampal tissues of $P D$ rats. The serum levels of IL-1 $1 \beta, I L-6, T N F-\alpha$, NF-KB p65 and COX-2 in PD rats were also significantly elevated. However, these increases were reversed by bacoside-A. Parkinson's disease (PD) is also influenced by overproduction of NO via DNA damage $[17,18]$. Previous studies have linked neuronal apoptosis with over-expressions of Bax, caspase-3, cytochrome $c$ and p53, as well as suppression of Bcl-2 [19-22]. In the present study, Bax, caspase-3, cytochrome c and p53 were upregulated, whereas $\mathrm{Bcl}-2$ was suppressed in $P D$ rats. However, bacoside- $A$ treatment reversed the $P D$-induced increases in expressions of $\mathrm{Bcl}-2$, caspase-3, cytochrome c and p53 in the rats.

\section{CONCLUSION}

Bacoside-A exhibits protective effect against Parkinson disease-induced oxidative damage and neuronal degeneration in rats via a mechanism involving the suppression of iNOS, AChE, inflammatory cytokines and pro-apoptotic proteins. Therefore, bacoside-A has some promise for use in the management of Parkinson disease.

\section{DECLARATIONS}

\section{Conflict of interest}

No conflict of interest is associated with this work.

\section{Contribution of authors}

We declare that this work was done by the author(s) named in this article and all liabilities pertaining to claims relating to the content of this article will be borne by the authors. Binbin Zhang, Jiankuan Shi, and Lei Chang contributed to this work equally. Yijun Song - conceived and designed the study; Binbin Zhang, Jiankuan Shi, Lei Chang, Hong Wang, Yaping Wang, Minxia Li, Yuying $\mathrm{Li}$ - collected and analyzed the data; Binbin Zhang, Jiankuan Shi, Lei Chang -wrote the manuscript. All authors read and approved the manuscript for publication.

\section{Open Access}

This is an Open Access article that uses a funding model which does not charge readers or 
their institutions for access and distributed under the terms of the Creative Commons Attribution License (http://creativecommons.org/licenses/by/ 4.0) and the Budapest Open Access Initiative (http://www.budapestopenaccessinitiative.org/rea d), which permit unrestricted use, distribution, and reproduction in any medium, provided the original work is properly credited.

\section{REFERENCES}

1. González-Burgos E, Fernandez-Moriano C, GómezSerranillos MP. Potential neuroprotective activity of Ginseng in Parkinson's disease: A review. J Neuroimmune Pharmacol 2015; 10: 14-29.

2. Rektor I, Goldemund $D$, Bednarik $P$, Bednařik $P$, Sheardová K, Michálková Z, Telecká S, Dufek M, Rektorová I. Impairment of brain vessels may contribute to mortality in patients with Parkinson's disease. Mov Disord 2012; 27: 1169-1172.

3. Fuxe K, Marcellino D, Genedani S, Agnati L. Adenosine $A(2 A)$ receptors, dopamine $D(2)$ receptors and their interactions in Parkinson's disease. Mov Disord 2007; 22: 1990-2017.

4. Tapias V, Cannon JR, Greenamyre JT. Pomegranate juice exacerbates oxidative stress and nigrostriatal degeneration in Parkinson's disease. Neurobiol Aging 2014; 35: 1162-1176.

5. Prigione A, Isaias IU, Galbussera A, Brighina L, Begni B, Andreoni S, Pezzoli G, Antonini A, Ferrarese C. Increased oxidative stress in lymphocytes from untreated Parkinson's disease patients. Parkinsonism Relat Disord 2009; 15: 327-328.

6. Tassorelli C, Furnari A, Buscone S, Alfonsi E, Pacchetti C, Zangaglia R, Pichiecchio A, Bastianello S, Lozza A, Allena M. Pisa syndrome in Parkinson's disease: Clinical, electromyographic, and radiological characterization. Mov Disord 2012; 27: 227-235.

7. Anand T, Naika M, Swamy MS, Khanum F. Antioxidant and DNA damage preventive properties of Bacopa monniera (L) Wettst. Free Rad Antioxidants 2011; 1: 8995.

8. Singh HK, Dhawan BN. Neuropsychopharmacological effects of Ayurvedic noortropic Bacopa monniera Linn. (Brahmi). Indian J Pharmacol 1997; 29:S359-65.

9. Kohl Z, Ben Abdallah N, Vogelgsang J, Tischer L, Deusser J, Amato D, Anderson S, Müller CP, Riess O, Masliah E, et al. Severely impaired hippocampal neurogenesis associates with an early serotonergic deficit in a BAC $\alpha$-synuclein transgenic rat model of Parkinson's disease. Neurobiol Dis 2016; 85: 206-217.

10. Kumar R, Hauser RA, Mostillo J, Dronamraju N, Graf A, Merschhemke M, Kenney C. Mavoglurant (AFQ056) in combination with increased levodopa dosages in Parkinson's disease patients. Int J Neurosci 2013; 126: 20-24.
11. Lu J, Wu L, Jiang T, Wang $Y$, Zhao $H$, Gao Q, Pan $Y$, Tian $Y$, Zhang $Y$. Angiotensin AT2 receptor stimulation inhibits activation of NADPH oxidase and ameliorates oxidative stress in rotenone model of Parkinson's disease in CATHa cells. Neurotoxicol Teratol 2015; 47: 16-24.

12. Steultjens MP, Stolwijk-Swüste J, Roorda LD, Dallmeijer AJ, van Dijk GM, Post B, Dekker J. CARPA Study Group: WOMAC-pf as a measure of physical function in patients with Parkinson's disease and late-onset sequels of poliomyelitis: Unidimensionality and item behaviour. Disabil Rehabil 2012; 34: 1423-1430.

13. Antonini A, Tinazzi M. Targeting pain in Parkinson's disease. Lancet Neurol 2015; 14: 1144-1145.

14. Soares $D G$, Godin AM, Menezes RR, Nogueira RD, Brito AM, Melo IS, Coura GM, Souza DG, Amaral FA, Paulino $T P$, et al. Anti-inflammatory and antinociceptive activities of azadirachtin in mice. Planta Med 2014; 80: 630-636.

15. Wu XL, Wang P, Liu YH, Xue YX. Effects of poly (ADPribose) polymerase inhibitor 3-aminobenzamide on blood-brain barrier and dopaminergic neurons of rats with lipopolysaccharide-induced Parkinson's disease. J Mol Neurosci 2014; 53: 1-9.

16. Rohn TT, Catlin LW. Immunolocalization of influenza A virus and markers of inflammation in the human Parkinson's disease brain. PLoS One 2011; 6: e20495.

17. Huerta C, Sánchez-Ferrero E, Coto E, Blázquez M, Ribacoba R, Guisasola LM, Salvador C, Alvarez V. No association between Parkinson's disease and three polymorphisms in the eNOS, nNOS, and iNOS genes. Neurosci Lett 2007; 413: 202-205.

18. Pontone GM, Palanci J, Williams JR, Bassett SS. Screening for DSM-IV-TR cognitive disorder NOS in Parkinson's disease using the Mattis Dementia Rating Scale. Int J Geriatr Psychiatry 2013; 28: 364-371.

19. Zhu L, Zhu B, Yang L, Zhao X, Jiang H, Ma F. RelB regulates $B C l-x l$ expression and the irradiation-induced apoptosis of murine prostate cancer cells. Biomed Rep 2014; 2: 354-358.

20. Shrivastava $P$, Vaibhav $K$, Tabassum $R$, Khan A, Ishrat $T$, Khan MM, Ahmad A, Islam F, Safhi MM, Islam F. Anti-apoptotic and anti-inflammatory effect of Piperine on 6-OHDA induced Parkinson's rat model. J Nutr Biochem 2013; 24: 680-687.

21. Yasuda $T$, Hayakawa $H$, Nihira $T$, Ren $Y R$, Nakata $Y$, Nagai M, Hattori N, Miyake K, Takada M, Shimada T, et al. Parkin-mediated protection of dopaminergic neurons in a chronic MPTP-minipump mouse model of Parkinson disease. J Neuropathol Exp Neurol 2011; 70: 686-697.

22. Manosroi A, Kitdamrongtham W, Ishii K, Shinozaki $T$, Tachi Y, Takagi M, Ebina K, Zhang J, Manosroi J, Akihisa R, Akihisa T. Limonoids from Azadirachta indica var. siamensis extracts and their cytotoxic and melanogenesis-inhibitory activities. Chem Biodivers 2014; 11: 505-531.

Trop J Pharm Res, December 2020; 19(12): 2570 